\title{
Alcohol consumption among Chilean adolescents: Examining individual, peer, parenting and environmental factors
}

\author{
Guillermo E. Sanhueza ${ }^{1}$, Jorge Delva ${ }^{1}$, Cristina B. Bares ${ }^{2}$, and Andrew Grogan-Kaylor ${ }^{1}$ \\ ${ }^{1}$ School of Social Work, University of Michigan, Ann Arbor, MI, United States \\ ${ }^{2}$ School of Social Work, Virginia Commonwealth University, Richmond, VA, United States
}

\begin{abstract}
Aims: This study examined whether adolescents from Santiago, Chile who had never drunk alcohol differed from those who had drunk alcohol but who had never experienced an alcohol-related problem, and from those who had drunk alcohol and who had experienced at least one alcohol-related problem, on a number of variables from four domains: individual, peers, parenting, and environment.
\end{abstract}

Design: Cross-sectional.

Setting: Community-based sample.

Participants: 909 adolescents (48.8\% females), from Santiago, Chile, mean age 14.5 years old.

Measurement: Data were analyzed with multinomial logistic regression to compare adolescents who had never drunk alcohol (non-drinkers) with (i) those who had drunk alcohol but had not experienced alcohol-related problems (non-problematic drinkers) and (ii) those who had drunk alcohol and had experienced at least one alcohol-related problem (problematic drinkers). The analyses included individual, peer, parenting, and environmental factors, while controlling for age, sex, and socioeconomic status.

Findings: Compared to non-drinkers, both non-problematic and problematic drinkers were older and reported having more friends who drank alcohol, greater exposure to alcohol ads, lower levels of parental monitoring, and more risk-taking behaviors. In addition, problematic drinkers placed less importance on guidance from religious faith when making daily life decisions and had higher perceptions of neighborhood crime than non-drinkers.

Conclusions: Prevention programs aimed at decreasing problematic drinking could benefit from helping adolescents draw upon their spiritual sources of strength, ensuring that parents have the tools to monitor their adolescents, and improving environmental and neighborhood conditions.

In Chile, drinking alcohol constitutes a culturally normative behavior, with more than $50 \%$ of the population between 15-64 years consuming alcohol and approximately 17\% considered problematic drinkers (United Nations Office for Drug Control, 2008). Although the past-month prevalence of alcohol consumption among school-aged youth dropped from 43.3\% to 35.5\% between 2005 and 2009 (Chilean Commission for the Control of Illegal Substances, 2009), a high percentage of youth still engage in risky drinking behaviors. For example, the corresponding percentages of 16- to 17-year-olds who, in 2009, reported getting drunk at least three times during the past year and drinking five or more drinks during a Saturday night were $18.7 \%$ and
16.4\%, respectively (Chilean Commission for the Control of Illegal Substances, 2009). These data are of serious concern, given that adolescent drinking is a behavior associated with numerous health, social, academic and economic consequences (Fergusson \& Lynskey, 1996; Miller \& Plant, 1999; Rudatsikira, Muula, \& Siziya, 2008; World Health Organization [WHO], 2004).

According to eco-developmental theory (Szapocznik \& Coatsworth, 1999), to better understand problematic drinking, factors from multiple contexts need to be considered. At the individual level, having a sense of hope (Wilson, Syme, Boyce, Battistich, \& Selvin, 2005) and

Correspondence: Guillermo Sanhueza, School of Social Work, University of Michigan 1080 S. University, Ann Arbor, MI, United States Telephone: 734-763-5768, Fax: 734-615-3192, E-mail: gesanhue@umich.edu

Financial support: U.S. National Institute on Drug Abuse R01 DA DA021181 and Vivian A. and James L. Curtis School of Social Work Research and Training

Center, University of Michigan.

Word count (exclusive of abstract, references, tables and figures): 4,075

Keywords: adolescents, drinking, alcohol, risk and protective factors, Chile 
cultivating religiosity or spirituality (Hodge, Andereck, \& Montoya, 2007; Mason \& Windle, 2001) are examples of protective factors. In contrast, risk-taking behaviors and externalizing problem behaviors (King \& Vidourek, 2010) are risk factors for alcohol use and for progression to deleterious use. Peers have been found to influence adolescents' drinking behaviors over and above individual characteristics (Brenner, Bauermeister, \& Zimmerman, 2011; Lopez et al., 2008). At the familial level, lack of communication and cohesion among family members, as well as parental substance use, have been found to be associated with adolescent misuse of alcohol (Bares, Delva, Grogan-Kaylor, \& Andrade, 2011; Santander et al., 2008). On the other hand, strong family bonds (Caldwell et al., 2006) and parental monitoring (Latendresse et al., 2008; Valenzuela, 2006) have been found to protect against alcohol use and its progression into alcohol-related problems.

In terms of the environment, alcohol advertising, and marketing have been found to be associated with alcohol use among adolescents (Anderson, De Bruijn, Angus, Gordon, \& Hastings, 2009; Morgenstern, Isensee, Sargent, \& Hanewinkel, 2011). Furthermore, research on neighborhood influences suggests that some characteristics are associated with adolescent substance use via differential exposure opportunities, such as greater alcohol outlet density or availability of illicit drugs (Storr, Chen, \& Anthony, 2004; Wagner \& Anthony, 2002).

For the most part, the extant literature examining the role of multiple influences on adolescent drinking comes from developed countries (Faggiano et al., 2005), and research conducted in Chile has not considered environmental factors as potential predictors of alcohol use. For example, Santander et al. (2008) found that family is an important protective factor in the prevention of risk behaviors in Chilean adolescents, and Valenzuela (2006) provided evidence of the protective role that parental monitoring has on adolescent substance use, but neither of these studies included environmental variables. Recognizing the complexities associated with substance use (Horner et al., 2011), the need to study a variety of sources of influences to better inform substance use prevention among adolescents (Buu et al., 2009), and the gaps in knowledge on adolescent alcohol use in Latin America, we conducted a study that examined the degree to which a number of individual, peer, parenting, and environmental variables were associated with non-problematic and problematic alcohol use among Chilean adolescents.

\section{METHOD}

\section{Sample and Procedures}

The study included 1,076 adolescents who were interviewed between 2007 and 2010 as part of a substance use study in Santiago, Chile. These adolescents were recruited from a sample of 1,700 mothers and healthy infants who had participated in a study of developmental and behavioral effects of iron supplementation when these youths were infants (1991-1996) (Lozoff et al., 2003) and later when they were 10 years old (2001-2007) (Lozoff, Castillo, Clark, \& Smith, 2012). These families were recruited, when the youth were infants, from a convenience sample of women of middle to low socioeconomic status who visited community health centers in four workingclass neighborhoods in Santiago.

The adolescents completed a two-hour, paper-and-pencil, interviewer-administered questionnaire in a private room at the study site (a university-based research center) in Chile. Prior to the commencement of the study, the Englishlanguage measures in the questionnaire had been translated into Spanish by a team of Spanish-speaking investigators in the United States. Then, the research team in Chile reviewed the translated measures and made recommendations to ensure linguistic and conceptual equivalence across the translations. Subsequently, the questionnaire, including both the translated items (i.e., questions about religiosity and spirituality) and other measures that were already available in Spanish and commonly used in Chile (i.e., substance-use questions utilized in the national school surveys of school-attending youth in Chile), was tested with 30 youth of the same age as those in the study sample. Youth were asked to comment on the readability and comprehensibility of the items. Modifications, albeit quite minor, were made to the measures based on the youth feedback.

Questionnaire administration was done by psychologists who specialized in behavioral health with children and families. Sitting at a desk, across from the adolescent, the psychologist read the questions, and the adolescent wrote their answers on their own questionnaire. At the completion of the interview, the interviewer placed the questionnaire in an envelope and then in a file cabinet that remained locked at all times in one of the project offices. Data entry took place within the next 48 hours if possible, or within two weeks at the latest, by staff hired to enter data. The questionnaire included comprehensive questions on substance use, individual, peer, parental, familial, school, and neighborhood-related factors.

The total of 1,076 adolescents in the original sample was reduced to an analytic sample of 909; participants were excluded mainly because they did not answer the three questions related to school prevention efforts, or they had missing data on some of the other variables. A comparison of the means of the variables included in this study between the analytic sample $(N=909)$ and the excluded sample ( $N$ $=167$ ) revealed no differences in the sex of the participants but did reveal the following differences: adolescents in the excluded sample were older; had higher socioeconomic status; more likely to have parents who used drugs; lower levels of spirituality, less parental monitoring, and lower family involvement.

\section{Measures}

Problematic alcohol use. This variable consisted of three categories: (1) youth who indicated they had never drunk alcohol in their lives, (2) those who at some point in their lives had drunk alcohol but had not experienced any alcohol-related problems, and (3) those who had drunk 
alcohol and had experienced at least one alcohol-related problem from a list of 14 possible problems. Youth were first asked if they had ever consumed alcohol. Those who answered affirmatively were asked if their consumption of alcohol had ever caused them any problems from a list of 14 possible problems. The stem question was, "Has your use of alcohol ever caused any of the following problems for you?" Examples of problems were: "caused you to behave in ways that you latter regretted" and "interfered with your ability to think clearly," with yes-no response options. These questions were adapted from surveys of school-attending youth in the United States (Johnston, Bachman, \& O'Malley, 2005) and in Chile (Chilean Commission for the Control of Illegal Substances, 2009). Youth who endorsed at least one item were categorized as having experienced an alcohol-related problem. We initially created two categories of problematic drinkers: youth with 1-2 alcohol-related problems, and those with 3 or more. Because the results of the inferential analyses were similar for these groups, and in order to increase statistical power, we combined the two categories into one group (1 or more problems).

Self-esteem. The Child Health and Illness Profiles (CHIP) subscale for self-esteem was used to assess this construct (Riley, Green et al., 1998, Riley, Forrest et al., 1998). Youth were asked the extent to which they agreed with each of nine statements about themselves, such as "I am satisfied with how I live my life," with response options: "1=Do not agree," "2=Agree a little," " $3=$ Mostly agree," and "4=Completely agree." Responses were summed to create a composite score, with higher scores representing more self-esteem (Cronbach's $\alpha=0.83$ ).

Risk-taking behavior. The CHIP subscale for risk-taking behavior was utilized to assess this construct (Riley, Green et al., 1998; Riley, Forrest et al., 1998). Youth were asked when they had last engaged in any one of 13 behaviors, such as carrying a weapon, with the following response categories: " $1=$ Never," " $2=$ More than a year ago," " $3=$ In the past year," " $4=$ In the past month," and " $5=$ In the past week." Responses were summed to create a composite score, with higher scores representing engagement in more risky behaviors $(\alpha=0.74)$.

Importance of religious faith. Youth were asked: "How important or unimportant is religious faith in how you live your daily life?" and "How important or unimportant is religious faith in making major life decisions?" with response categories being " $1=$ Not important at all," " $2=$ Not very important," "3=Somewhat important," "4=Very important," and " $5=$ Extremely important." A composite score was created, with higher scores indicating greater importance of faith in informing daily-life activities and decisions $(\alpha=0.85)$.

Number of peers who drank alcohol. The CHIP subscale on peer influence was utilized to assess this construct (Riley, Green et al., 1998; Riley, Forrest et al., 1998). Youth were asked how many of their friends drank alcoholic beverages, with response categories being "1=None," "2=A few," "3=Some," "4=Most,” and "5=All.”
Peer pressure to use substances. To assess peer pressure, the CHIP subscale that asks about peer pressure was utilized (Riley, Green et al., 1998; Riley, Forrest et al., 1998). Youth were asked, "How much pressure do you feel from your friends and schoolmates to..." (1) smoke cigarettes, (2) drink alcoholic beverages, (3) use marijuana, and (4) use other illegal drugs. Response categories were " $1=$ None," " $2=\mathrm{A}$ little," " $3=$ Some," and " $4=\mathrm{A}$ lot." Responses were summed to create a composite score, with higher scores representing more peer pressure to use substances $(\alpha=0.86)$.

Parental monitoring. Youth reports of parental monitoring were assessed using seven questions taken from an instrument initially designed by the Oregon Social Learning Center (1990). A sample question is, "How often do you check in with your mom/dad or guardian after school before going to hang out with friends?" with response categories being " $1=$ All of the time," " $2=$ Most times," " $3=$ Sometimes," " $4=$ Hardly ever," and " $5=$ Never." After reverse coding, a composite score was created, with higher scores representing more parental monitoring ( $\alpha=$ 0.65).

Parental alcohol use. Youth were asked if they thought their parents or main caregiver had drunk alcohol in the past 12 months, with response categories being "4=Definitely yes,” "3=Probably yes,” "2=Probably no,” “1=Definitely no.”

Parental drug use. Youth were asked if during the past 12 months they thought their parent or main caregiver had tried (1) marijuana, (2) cocaine, or (3) other illicit drugs, with response categories being " $4=$ Definitely yes," "3=Probably yes,” "2=Probably no,” " $1=$ Definitely no.” Responses were summed to create a composite score, with higher scores indicating greater perception of parental drug use $(\alpha=0.77)$.

Family involvement. The CHIP subscale on family involvement was utilized to assess this construct (Riley, Green et al., 1998; Riley, Forrest et al., 1998). Youths were asked five questions about their perceptions of their family involvement. The stem question for three of them was, "Thinking about your family, about how many days in the past four weeks did your parents or other adults in your family..." An example of an ending to this question is, "Spend time with you doing something fun?" The response categories were " $1=$ No days," " $2=1$ to 3 days," " $3=4$ to 6 days," " $4=7$ to 14 days," and " $5=15$ to 28 days." The stem for the other two questions was, "In the past 4 weeks, on how many days..." An example of an ending to this question is, "Have you liked being a member of your family?" The response categories were the same. A composite score was created for all five responses, with higher scores representing more family involvement ( $\alpha=$ $0.74)$.

Perception of neighborhood crime. Youth were asked three questions that assessed the extent to which they perceived their neighborhood as being affected by crime (Program for Research on Black Americans, 2001): "How 
often are there problems with muggings, burglaries, assaults, or anything else like that in your neighborhood? Would you say..." with the response categories being "1=Never," "2=Hardly ever," " $3=$ =Not too often," "4=Fairly often," and " $5=$ Very often"; "How much of a problem is the selling and use of drugs in your neighborhood? Would you say this problem is..." with response categories of " $1=$ Never," " $2=$ Not serious at all," " $3=$ Not too serious," " $4=$ Fairly serious," and " $5=$ Very serious"; and "During the past 12 months, how often have you seen people selling illegal drugs in your neighborhood?" with the response categories being " $1=$ Never," " $2=\mathrm{A}$ few times a year," " $3=$ Once or twice a month," " $4=$ At least once a week," and " $5=$ Almost every day." Responses were summed to create a composite score, with higher scores representing higher perceptions of crime $(\alpha=0.71)$.

Exposure to alcohol advertisements. Youth were asked two questions to measure exposure to alcohol advertisements. The questions were, "In recent months, about how often have you seen commercials on TV, or heard them on the radio, that encourage you to buy and drink alcohol (beer, wine, liquor)?” and, "In recent months, about how often have you seen ads on billboards or in magazines or newspapers that encourage you to buy and drink alcohol (beer, wine, liquor)?” Response categories were " $1=$ Not at all," " $2=$ Less than once a month," " $3=1-3$ times a month," " $4=1-3$ times per week," " $5=$ daily or almost daily," and "6=More than once a day," with higher scores representing greater exposure to alcohol ads $(\alpha=$ $0.65)$.

School efforts to prevent substance use. Youth were asked, "In your present school, how vigorous are the teachers and administrators in their attempts to prevent students from..." (1) smoking, (2) alcohol, and (3) drug use. Response categories were " $1=$ Not at all," "2=Slightly," "3=Somewhat," "4=Fairly rigorous," and " $5=$ Very rigorous." Responses were tallied to create a composite score, with higher scores representing more perceived prevention efforts $(\alpha=0.90)$.

Demographics. Age and sex were based on self-report. Socioeconomic status (SES) was based on parents' answers to 13 questions from the Graffar instrument (Graffar, 1956), which includes questions about a number of social characteristics of families and households in developing countries, including sources of income, type of occupation of those who work, their level of instruction, and general characteristics of the home, among others. It has been frequently used in Chile (Álvarez, Muzzo, \& Ivanovic, 1985; Gahagan, Yu, Kaciroti, Castillo, \& Lozoff, 2009) and in other developing countries (Lorenzana \& Sanjur, 1999; Raaijmakers, Gajjar, Schröder, \& Nourse, 2010; Viana, Sinde, \& Saxton, 2008). The sum of the items in the Graffar results in a classification of households into five categories, where higher scores indicate higher socioeconomic status. The measure was completed by the parent or adult caregiver who brought the youth to the interview site.

\section{Analysis}

Data were analyzed with ANOVA and chi-squared statistics to compare the distribution of the variables among the three alcohol-use categories (non-drinkers, drinkers with no alcohol-related problems, and those labeled problematic drinkers). These bivariate analyses were followed with multivariate multinomial logistic regression, with "non-drinkers" as the comparison. Therefore, two separate regression equations estimated the relative risks of being a drinker with no alcohol problems as compared to a non-drinker, and the relative risks of being a drinker with alcohol problems as compared to a non-drinker. All analyses were conducted with STATA 9.0 (StataCorp, 2008).

\section{RESULTS}

Approximately $48.8 \%$ of the study participants were female and the average age was 14.5 years. Of the 909 youth, 497 (54.7\%) reported never having consumed alcohol, 269 (29.6\%) had consumed alcohol but reported no alcoholrelated problems, and $143(15.7 \%)$ had consumed alcohol and reported at least one alcohol-related problem. As shown in Table 1 , the percentages of males and females, the mean family socioeconomic status, and self-esteem did not differ by drinking category. On the other hand, problematic drinkers were older $(M=15.6$ years) than drinkers without alcohol-related problems $(M=14.9)$, who in turn were older than non-drinkers $(M=13.9)(p<.001)$. Correspondingly, the mean number of risk-taking behaviors and the number of friends who drank were higher among problematic drinkers and drinkers who did not report alcohol-related problems $(p<.001)$. Peer pressure to drink was highest among problematic drinkers. The importance of religious faith in guiding decision-making was higher among non-drinkers $(M=6.6)$ and drinkers with no alcohol-related problems $(M=6.30)$ than among problematic drinkers $(M=5.7)(p<0.01)$. Mean levels of parental monitoring were higher among non-drinkers $(M=$ 28.8), followed by drinkers without alcohol-related problems $(M=26.8)$, who in turn had higher levels of parental monitoring than problematic drinkers $(M=25.2)$ $(p<0.001)$. Family involvement was higher among nondrinkers $(M=19.3)$ than among drinkers without problems $(M=26.8)$ and those with drinking-related problems ( $M=$ 25.2) $(p<0.001)$. Parental use of alcohol and other drugs was lowest among non-drinkers. Finally, reports of neighborhood crime and exposure to alcohol ads were higher among drinkers with no alcohol-related problems and problematic drinkers, and school alcohol prevention efforts were higher among non-drinkers and drinkers with no alcohol-related problems.

Following the bivariate comparisons, multivariate multinomial logistic regressions were conducted to compare the three alcohol-use categories simultaneously on the variables from all four domains included in this study. These results are described next. 
Table 1

Sample characteristics and comparisons as a function of drinking status $(N=909)$

\begin{tabular}{|c|c|c|c|c|c|c|c|}
\hline \multirow[b]{2}{*}{ Domain/Variable } & \multicolumn{2}{|c|}{$\begin{array}{l}\text { Non-drinkers } \\
\quad(n=497)\end{array}$} & \multicolumn{2}{|c|}{$\begin{array}{l}\text { Drinkers with no } \\
\text { alcohol-related } \\
\text { problems } \\
(n=269)\end{array}$} & \multicolumn{2}{|c|}{$\begin{array}{c}\text { Problematic } \\
\text { drinkers } \\
(n=143)\end{array}$} & \multirow[b]{2}{*}{ Sig. } \\
\hline & $M / \%$ & $S D$ & $M / \%$ & $S D$ & $M / \%$ & $S D$ & \\
\hline \multicolumn{8}{|l|}{ Demographics } \\
\hline Sex (\% females) & 51.90 & -- & 44.20 & -- & 46.80 & -- & ns \\
\hline SES & 33.37 & 6.96 & 32.57 & 6.54 & 33.18 & 6.51 & ns \\
\hline Age & 13.89 & 1.24 & 14.92 & 1.48 & 15.57 & 1.37 & $\mathrm{a}, \mathrm{b}, \mathrm{c} * * *$ \\
\hline \multicolumn{8}{|l|}{ Individual } \\
\hline Self-esteem & 28.28 & 4.37 & 27.81 & 4.95 & 27.34 & 4.79 & $n s$ \\
\hline Risk-taking behavior & 15.76 & 3.63 & 17.34 & 4.89 & 20.15 & 6.11 & a,b,c*** \\
\hline Importance of religious faith & 6.55 & 1.95 & 6.30 & 2.03 & 5.68 & 2.08 & $\mathrm{~b}^{* * *}, \mathrm{c}^{*}$ \\
\hline \multicolumn{8}{|l|}{ Peers } \\
\hline Number of friends drinking & 1.95 & 1.00 & 2.71 & 1.08 & 3.45 & 1.11 & a,b,c*** \\
\hline Peer pressure to drink & 4.69 & 2.06 & 4.72 & 1.83 & 5.50 & 2.50 & $\mathrm{~b}^{* * *}, \mathrm{c}^{* *}$ \\
\hline \multicolumn{8}{|l|}{ Parenting and family } \\
\hline Parental monitoring & 28.80 & 4.60 & 26.78 & 5.55 & 25.15 & 5.30 & $\mathrm{a}, \mathrm{b}^{* * *}, \mathrm{c}^{* *}$ \\
\hline Parental drug use & 3.51 & 1.45 & 3.55 & 1.43 & 3.94 & 1.83 & $\mathrm{~b}, \mathrm{c}^{* *}$ \\
\hline Parental alcohol use & 3.30 & 1.01 & 3.51 & 0.90 & 3.53 & 0.85 & $\mathrm{a}, \mathrm{b}^{*}$ \\
\hline Family involvement & 19.30 & 3.90 & 17.98 & 4.58 & 17.19 & 4.48 & $\mathrm{a}, \mathrm{b}^{* * *}$ \\
\hline \multicolumn{8}{|l|}{ Environment } \\
\hline Crime level in neighborhood & 8.45 & 3.23 & 9.29 & 3.16 & 10.25 & 3.06 & $\mathrm{a}, \mathrm{c}^{* *}, \mathrm{~b}^{* * *}$ \\
\hline Exposure to alcohol ads & 2.14 & 0.59 & 2.33 & 0.77 & 2.69 & 1.13 & $a^{* *}, b, c^{* * *}$ \\
\hline School preventive efforts & 12.33 & 2.80 & 11.72 & 3.09 & 11.54 & 3.20 & $\mathrm{a}, \mathrm{b}^{*}$ \\
\hline
\end{tabular}

$* p<.05 ; * * p<.01 ; * * * p<.001$

Note. Column labeled "Sig." refers to whether the differences between the means (or percents) of each variable across the three categories of youth (drinkers, drinkers with no alcohol-related problems, and those with alcohol-related problems) are statistically significant. Means were compared with ANOVA, and pair-wise contrasts, with Scheffe post-hoc test. The distribution of gender, the only categorical variable, was compared with the chi-square statistic. Results are reported as follows: " $n s$ " refers to difference not being statistically significant; "a" refers to statistically significant differences between 'non-drinkers' and 'drinkers with no-alcohol-related problems'; “b” refers to statistically significant differences between 'non-drinkers' and 'problematic drinkers'; 'c' refers to statistically significant differences between 'drinkers with no alcoholrelated problems' and ‘problematic drinkers'.

\section{Non-drinkers versus drinkers with no alcohol- related problems.}

Compared to youth who never drank alcohol, those who drank but had no alcohol-related problems were older (Relative Risk Ratio $[R R R]=1.56$; 95\% CI = 1.36-1.79), had engaged in more risk-taking behaviors $(R R R=1.05$; $95 \% \mathrm{CI}=1.00-1.09)$, had more drinking peers $(R R R=$ 1.42; $95 \% \mathrm{CI}=1.20-1.68)$, had less parental monitoring $(R R R=0.95 ; 95 \% \mathrm{CI}=0.91-0.98)$, and had been exposed to more alcohol ads $(R R R=1.41 ; 95 \% \mathrm{CI}=1.10-1.80)$ (see Table 2, left panel).

\section{Non-drinkers versus drinkers with alcohol-related problems.}

Compared to youth who never drank alcohol, those with problematic drinking were older $(R R R=1.95 ; 95 \% \mathrm{CI}=$ 1.62-2.33), had engaged in more risk-taking behaviors $(R R R=1.11 ; 95 \%$ CI $=1.05-1.17)$, reported lower importance of religious faith in making decisions $(R R R=$ 0.86 ; $95 \% \mathrm{CI}=0.76-0.97)$, had more drinking peers $(R R R$ $=2.25 ; 95 \% \mathrm{CI}=1.76-2.87)$, less parental monitoring $(R R R=0.93 ; 95 \% \mathrm{CI}=0.88-0.98)$, perceived more crime in their neighborhoods $(\mathrm{RRR}=1.08 ; 95 \% \mathrm{CI}=1.00-1.17)$, and were exposed to more alcohol ads $(R R R=1.85 ; 95 \%$ CI $=1.40-2.44)$ (see Table 2, right panel).

\section{Discussion}

The economic growth that Latin America has experienced in recent years has been accompanied by persistent, overlapping inequalities and a variety of social problems. Extreme inequalities are evident in Chile (Lopez \& Perry, 2008), and have negatively affected levels of mutual trust and confidence toward institutions (United Nations, Program for Human Development, 2009). These social insecurities, coupled with the well-documented culturallyrooted 'festive' traditions of the region (Garcia-Pabón, 2010; Kennedy, 1996), where alcohol is a culturallyaccepted substance that enhances people's ties and social life (Castaño-Perez, 2008; Chávez \& Andrade, 2005), have created a socio-cultural context where alcohol is used to ameliorate the daily-life struggles of the Chilean population. 
Table 2

Association of individual, peer, parenting and family, and environmental variables with non-problematic and problematic drinking: Results of multivariate multinomial logistic regression analysis

\begin{tabular}{|c|c|c|c|c|c|c|}
\hline \multirow[b]{2}{*}{ Domain/Variable } & \multicolumn{3}{|c|}{$\begin{array}{c}\text { Non-problematic drinkers vs. non- } \\
\text { drinkers }\end{array}$} & \multicolumn{3}{|c|}{$\begin{array}{c}\text { Problematic drinkers } \\
\text { vs. non-drinkers } \\
\end{array}$} \\
\hline & $\begin{array}{c}\text { Relative Risk } \\
\text { Ratio }\end{array}$ & \multicolumn{2}{|c|}{$95 \%$ CI } & \multirow[t]{2}{*}{$\begin{array}{c}\text { Relative Risk } \\
\text { Ratio } \\
\end{array}$} & \multicolumn{2}{|c|}{ 95\% CI } \\
\hline \multicolumn{6}{|l|}{ Demographics } & \\
\hline Sex $(\operatorname{Ref}=F)$ & 0.74 & 0.51 & 1.06 & 1.09 & 0.64 & 1.84 \\
\hline SES & 0.98 & 0.96 & 1.00 & 1.00 & 0.97 & 1.04 \\
\hline Age & $1.56^{* *}$ & 1.36 & 1.79 & $1.94^{* *}$ & 1.62 & 2.33 \\
\hline \multicolumn{7}{|l|}{ Individual } \\
\hline Self-esteem & 0.99 & 0.95 & 1.03 & 0.99 & 0.94 & 1.05 \\
\hline Risk-taking behavior & $1.05 * *$ & 1.00 & 1.09 & $1.11^{* *}$ & 1.05 & 1.17 \\
\hline Importance of religious faith & 0.99 & 0.91 & 1.08 & $0.86 * *$ & 0.76 & 0.97 \\
\hline \multicolumn{7}{|l|}{ Peers } \\
\hline Number of friends drinking & $1.42 * *$ & 1.20 & 1.68 & $2.25 * *$ & 1.76 & 2.87 \\
\hline Peer pressure to drink & 0.94 & 0.86 & 1.03 & 1.05 & 0.95 & 1.16 \\
\hline \multicolumn{7}{|l|}{ Parenting } \\
\hline Parental monitoring & $0.95^{* *}$ & 0.91 & 0.98 & $0.93^{* *}$ & 0.88 & 0.98 \\
\hline Parental drug use & 0.92 & 0.82 & 1.04 & 0.96 & 0.83 & 1.12 \\
\hline Parental alcohol use & 1.16 & 0.97 & 1.40 & 1.16 & 0.88 & 1.52 \\
\hline Family involvement & 0.96 & 0.92 & 1.00 & 0.96 & 0.90 & 1.02 \\
\hline \multicolumn{7}{|l|}{ Environment } \\
\hline Crime level in neighborhood & 1.03 & 0.98 & 1.09 & $1.08 *$ & 1.00 & 1.17 \\
\hline Exposure to alcohol ads & $1.41^{* *}$ & 1.10 & 1.80 & $1.85 * *$ & 1.40 & 2.44 \\
\hline School prevention efforts & 0.99 & 0.93 & 1.04 & 1.05 & 0.96 & 1.13 \\
\hline
\end{tabular}

This relationship between "fiesta” and alcohol consumption also influences youth. Alcohol initiation, for example, usually takes place in a festive context among groups of peers or family members, and alcohol onset tends to occur early in the adolescent's life (Carlini-Cotrim, 1999). In addition, binge drinking among adolescents has become particularly high in many Latin American countries, especially in Chile (Villatoro et al., 2005).

By grouping youths according to their level of drinking and the consequences of drinking that they have experienced, more exact data may be derived, to better inform prevention and intervention strategies (Faggiano et al., 2005; Odgers et al., 2008). Based on this idea, this study placed Chilean adolescents who consumed alcohol into different categories, according to whether they had developed alcohol-related problems. Overall, the study findings are consistent with previous research showing that adolescents' drinking behaviors were associated with multiple factors (Lopez et al., 2008; Youngblade et al., 2007). A particularly interesting finding concerns the inverse association found between spirituality and experiencing alcohol-related problems, which is consistent with prior research (Hodge et al., 2007). These findings suggest that in this cultural context, promoting youth spirituality may play an important role in helping reduce the likelihood that adolescents will drink in deleterious ways (Puschel \& Cassigoli, 2009). However, the crosssectional design of the study prevents us from exploring the mechanisms by which religiosity and spirituality may act as protective factors against alcohol abuse in this sample.

Consistent with previous studies, peer influences were significantly associated with being a drinker and being a problematic drinker (Scholte, Poelen, Willemsen, Boomsma, \& Engels, 2008). With regards to parenting and family variables, parental monitoring was associated with lower odds of belonging to both groups of youths that drank (those with and without alcohol-related problems). Such findings are consistent with the literature identifying parental monitoring as a protective factor (Latendresse et al., 2008) and with the central role that families still play within Chilean society (Santander et al., 2008), despite the individualization and liberalization processes that have recently been taking place among Chilean youth (Cumsille, Darling, \& Martínez, 2010).

Exposure to alcohol advertising was found to be associated with a higher risk of belonging to both groups of drinkers, which is also consistent with prior research (Anderson et al., 2009). In terms of neighborhood conditions, the study findings suggest that increased levels of perceived crime in one's neighborhood are likely to be positively related to problematic drinking (Winstanley et al., 2008), which could be linked to spatial and social conditions that impact youths who live within marginalized areas of highly-segregated Santiago (Sabatini, 2004). 
Contrary to our expectations, no significant associations were observed between family involvement and alcohol use. It may be the case that low levels of variation in our measure of family involvement reduced our ability to detect a statistically significant association of this variable with our outcome of interest. Alternatively, drinking experiences may in some cases be part of family involvement within Latin American culture. In addition, in the multivariate model, youth reports of their parents' alcohol and other drug use were not significantly associated with drinking by the youth, independent of whether the youth experienced alcohol-related problems. This finding is interesting because other research with Chilean youth has shown parental drug consumption to be associated with adolescent marijuana use (Bares et al., 2011). It may be that differences in the types of substances used by parents, and in frequency of use and quantities used, result in differences in the effects on their adolescent children. In the absence of more detailed information about parental substance use, we could not examine these associations in more depth. We also did not find a significant association between adolescents' drinking behaviors and their perceptions of their schools' efforts to prevent substance use. This finding may suggest that other influences (peers, for example) are stronger than the influence of schoolcentered efforts, or even that the messages conveyed by the anti-substance programs that these youth have been exposed to have left no significant impression on them.

\section{Limitations of the Present Study}

The study findings should be interpreted within the context of the following limitations. First, data were from a crosssectional design, necessarily limiting statements one can make about the temporal associations among the variables. Second, all variables were based on adolescents' selfreports (except SES). In the case of their reports of neighborhood crime, it is plausible that objective reports (i.e., police reports of burglaries, robberies, drug arrests) may have given different findings. On the other hand, some research suggests that subjective perceptions of neighborhood conditions can make more of a contribution to understanding an outcome than objective characteristics derived from the census (Grogan-Kaylor et al., 2006; Weden, Carpiano, \& Robert, 2008). More research is certainly needed on the extent to which objective versus subjective measures of neighborhood characteristics are associated with youth alcohol consumption levels. Finally, not only were participants not randomly selected from a representative pool of Chilean adolescents, those included in the analyses differed from those in the analytic sample on several variables, altogether limiting the generalizability of the findings. Notwithstanding these limitations, this study is among the few to have studied alcohol behaviors among a Latin American sample of adolescents with a large number of variables representing multiple domains.

\section{Conclusions}

In conclusion, and consistent with prior research, the study findings highlight the complex and multi-dimensional nature of alcohol consumption and alcohol-related problems. Additional research is needed with Chilean youth and families to better understand the mechanisms by which the variables found to be inversely (e.g., youth spirituality) or positively (e.g., peer influences) correlated with alcohol-related problems may be influencing youth behaviors, in order to better inform alcohol prevention and intervention programs targeting adolescents in Chile.

\section{References}

Álvarez, M., Muzzo, S., \& Ivanovic, D. (1985). Escala para medición del nivel socioeconómico el área de la salud [Measurement of socioeconomic health]. Revista Médica de Chile, 113, 243-249.

Anderson, P., De Bruijn, A., Angus, K., Gordon, R., \& Hastings, G. (2009). Impact of alcohol advertising and media exposure on adolescent alcohol use: A systematic review of longitudinal studies. Alcohol and Alcoholism, 44, 229-243.

Bares, C., Delva, J., Grogan-Kaylor, A., \& Andrade, F. (2011). Family and parenting characteristics associated with marijuana use by Chilean adolescents. Substance Abuse and Rehabilitation, 2, $1-11$.

Brenner, A., Bauermeister, J., \& Zimmerman, M. (2011). Neighborhood variation in adolescent alcohol use: Examination of socioecological and social disorganization theories. Journal of Studies on Alcohol and Drugs, 72, 651-659.

Buu, A., DiPiazza, C., Wang, J., Puttler, L., Fitzgerald, H., \& Zucker, R. (2009). Parent, family, and neighborhood effects on the development of child substance use and other psychopathology from preschool to the start of adulthood. Journal of Studies on Alcohol and Drugs, 70, 489-498.

Caldwell, R., Sturges, S., Silver, N., Brinson, J., DenbyBrinson, R., \& Burgess, K. (2006). An examination of the influence of perceived parenting practices on depression and substance use among African American juvenile offenders. Journal of Forensic Psychology and Practice, 6, 31-50.

Carlini-Cotrim, B. (1999). Country profile on alcohol in Brazil. In L. Riley \& M. Marshall (Eds.), Alcohol and public health in eight developing countries (pp. 13-35). Geneva, Switzerland: Organización Mundial de la Salud (OMS).

Castaño-Perez, G. (2008). Aspectos socioculturales del consumo de alcohol en Latino America y estrategias de prevencion [Socio-cultural aspects of alcohol consumption in Latin America and prevention strategies]. Revista Analisis, 7, 15-30.

Chávez, L., \& Andrade, D. (2005). La escuela básica en la prevención del consumo de alcohol y tabaco: retrato de una realidad [Basic education in the prevention of alcohol and snuff: Portrait of a reality]. Revista Latino-Americana de Enfermagem, 13, 784-789.

Comisión Nacional para el Control de Estupefacientes [Chilean Commission for the Control of Illegal Substances] [CONACE]. (2009). Noveno estudio nacional de drogas en población escolar de Chile $20098^{\circ}$ Básico a $4^{\circ}$ Medio [Ninth national study on drugs on school-aged populations 2009]. Santiago de 
Chile, Chile: Ministerio del Interior, Gobierno de Chile.

Cumsille, P., Darling, N., \& Martinez, L. (2010). Shading the truth: The patterning of adolescents' decisions to avoid issues, disclose, or lie to parents. Journal of Adolescence, 33, 285-296.

Faggiano, F., Vigna-Taglianti, F., Versino, E., Zambon, A., Borraccino, A., \& Lemma, P. (2005). School based prevention for illicit drugs' use. Cochrane Database of Systematic Reviews, 2.

Fergusson, D., \& Lynskey, M. (1996). Alcohol misuse and adolescent sexual behaviors and risk taking. Pediatrics, 98, 91-96.

Gahagan, S., Yu, S., Kaciroti, N., Castillo, M., \& Lozoff, B. (2009). Linear and ponderal growth trajectories in well-nourished, iron-sufficient infants are unimpaired by iron supplementation. The Journal of Nutrition, 139, 2106-2112.

Garcia-Pabón, L. (2010). Indios, criollos y Fiesta Barroca en la historia de posotsi de Bartolomé Arzans [Indians, Creoles and Baroque Festival in Bartolomé Arzans' history of postí]. Revista Iberoamericana, $61,172-177$.

Graffar, M. (1956). Une méthode de classification sociale d'échantillons de population [A method for social classification of samples of population]. Courier, 6, 455-459.

Grogan-Kaylor, A., Woolley, M., Mowbray, C., Reischl, T. M., Gilster, M., Karb, R., . . . Alaimo, K. (2006). Predictors of neighbourhood satisfaction. Journal of Community Practice, 12, 27-50.

Hodge, D., Andereck, K., \& Montoya, H. (2007). The protective influence of spiritual-religious lifestyle profiles on tobacco use, alcohol use, and gambling. Social Work Research, 31, 211-219.

Horner, P., Grogan-Kaylor, A., Delva, J., Bares, C., Andrade, F., \& Castillo, M. (2011). The association of family and peer factors with tobacco, alcohol, and marijuana use among Chilean adolescents in neighborhood context. Substance Abuse and Rehabilitation, 2, 163-172.

Johnston, L., Bachman, J., \& O'Malley, P. (2005). Monitoring the future: A continuing study of American youth $\left(10^{\text {th }}\right.$ grade Survey), 2005 [computer file]. Ann Arbor, MI, United States: Inter-University Consortium for Political and Social Research. Retrieved from http://icpsr.com/SDA-CB/SAMHDA/ 04537-0008/CODEBOOK/45370009.htm

Kennedy, A. (1996). La fiesta barroca en Quito [The baroque festival in Quito]. Anales del Museo de America, 4, 137-152.

King, K., \& Vidourek, R. (2010). Psychosocial factors associated with recent alcohol use among Hispanic youth. Hispanic Journal of Behavioral Sciences, 32, 470-485.

Latendresse, S. J., Rose, R. J., Viken, R. J., Pulkkinen, L., Kaprio, J., \& Dick, D. M. (2008). Parenting mechanisms in links between parents' and adolescents' alcohol use behaviors. Alcoholism: Clinical and Experimental Research, 32, 322-330.

Lopez, H., \& Perry, G. (2008). Inequality in Latin America: Determinants and consequences. Policy Research
Working Paper Series, 4504. Washington, DC, United States: The World Bank.

Lopez, B., Schwartz, S., Prado, G., Huang, S., Rothe, E., Wang, W., \& Pantin, H. (2008). Correlates of early alcohol and drug use in Hispanic adolescents: examining the role of ADHD with comorbid conduct disorder, family, school, and peers. Journal of Clinical Child and Adolescent Psychology, 37, 820832.

Lorenzana, P., \& Sanjur, D. (1999). Abbreviated measures of food sufficiency validly estimate the food security level of poor households: Measuring household food security. The Journal of Nutrition, 129, 687-692.

Lozoff, B., De Andraca, I., Castillo, M., Smith, J., Walter, T., \& Pino, P. (2003). Behavioral and developmental effects of preventing iron-deficiency anemia in healthy full-term infants. Pediatrics, 112, 846-854.

Lozoff, B., Castillo, M., Clark, K., \& Smith, J. (2012). Iron-fortified vs. low-iron infant formula: Developmental outcome at 10 years. Archives of Pediatrics \& Adolescent Medicine, 166, 208-215.

Mason, W., \& Windle, M. (2001). Family, religious, school and peer influences on adolescent alcohol use: A longitudinal study. Journal of Studies on Alcohol, 62, 44-53.

Miller, P., \& Plant, M. (1999). Truancy and perceived social performance: An alcohol and rug study of UK teenagers. Alcohol and Alcoholism, 34, 886-893.

Morgenstern, M., Isensee, B., Sargent, J. D., \& Hanewinkel, R. (2011). Exposure to alcohol advertising and teen drinking. Preventive Medicine, 52, 146-151.

Odgers, C., Caspi, A., Nagin, D., Piquero, A., Slutske, W., Milne, B., . . . Moffitt, T. (2008). Is it important to prevent early exposure to drugs and alcohol among adolescents? Psychological Science, 19, 1037-1044.

Oregon Social Learning Center. (1990). Parental monitoring and supervision constructs (Technical Report). Eugene, OR, United States : Author. Retrieved from: http://www.oslc.org/

Program for Research on Black Americans. (2001). The National Survey of American Life: Coping with stress in the 21st century, adolescent interview. Institute for Social Research, University of Michigan. Ann Arbor, MI, United States: Program for Research on Black Americans. Retrieved from http://www.rcgd.isr. umich.edu/prba/questionnaires/nsaladolqn.pdf

Puschel, K., \& Cassigoli, G. (2009). Healthy development for healthy spirituality: social transformations among Chilean youth in the new millennium. In M. De Souza, L. Francis, J. O’Higgins-Norman, \& D. Scott, (Eds.), International handbook for education of spirituality (pp. 1075-1086). New York, NY, United States: Springer Publishing.

Raaijmakers, R., Gajjar, P., Schröder, C., \& Nourse, P. (2010). Peritonitis in children on peritoneal dialysis in Cape Town, South Africa: Epidemiology and risks. Pediatric Nephrology, 25, 2149-2157.

Riley, A., Green, B., Forrest, C., Starfield, B., Kang, M., \& Ensminger, M. (1998). A taxonomy of adolescent health: Development of the adolescent health profiletypes. Medical Care, 36, 1228-1236. 
Riley, A., Forrest, C., Starfield, B., Green, B., Kang, M., \& Ensminger, M. (1998). Reliability and validity of the adolescent health profile-types. Medical Care, 36, 1237-1248.

Rudatsikira, E., Muula A., \& Siziya, S. (2008). Prevalence and correlates of physical fighting among schoolgoing adolescents in Santiago, Chile. Revista Brasilera de Psiquiatria, 30, 197-202.

Sabatini, F. (2004). Medición de la segregación residencial: reflexiones metodológicas desde la ciudad latinoamericana [Measurement of residencial segregation: Methodological reflections from Latin American cities.]. In G. Cáceres \& F. Sabatini, (Eds.), Los Barrios Cerrados en Santiago de Chile: Entre la Exclusión y la Integración Social [Gated communities in Santiago Chile: Between exclusion and social integration] (pp. 276-307). Santiago, Chile: Instituto de Geografía, PUC Chile.

Santander, S., Zubarew, T., Santelices, L., Argollo, P., Cerda, J., \& Borquez, M. (2008). Influencia de la Familia como factor protector de conductas de riesgo en escolares chilenos [Family influence as a protective factor against risk behaviors among Chilean school-aged adolescents]. Revista Médica de Chile, 136, 317-324.

Scholte, R., Poelen, E., Willemsen, G., Boomsma, D., \& Engels, R. (2008). Relative risks of adolescent and young adult alcohol use: The role of drinking fathers, mothers, siblings, and friends. Addictive Behaviors, 33, 1-14.

StataCorp. (2008). STATA - Data analysis and statistical software. College Station, TX, United States: Author.

Storr, C., Chen, C., \& Anthony, J .C. (2004). Unequal opportunity: Neighbourhood disadvantage and the chance to buy illegal drugs. Journal of Epidemiology and Community Health, 58, 231-237.

Szapocznik, J. \& Coatsworth, J. (1999). An ecodevelopmental framework for organizing the influences on drug abuse: A developmental model of risk and protection. In M. Glantz \& C. Hartel (Eds.), Drug abuse: Origins and interventions (pp. 331366). Washington, DC, United States: American Psychological Association.

United Nations, Office for Drug Control [UNODC]. (2008). Subregional System of Information and Research on Drugs in Argentina, Chile, Bolivia, Ecuador, Peru, and Uruguay: First Comparative Study on Druge Use and Associated Factors in the General Population 15-64 years of age. New York, NY, United States: Author. Retrieved from http://www.cicad.oas.org/OID/NEW/Research/Execu tiveSummary-2008subregional.pdf

United Nations, Program for Human Development [PNUD]. (2009). Informe de desarrollo humano en Chile 2009 [Human development report: Chile]. New York, NY, United States: Author.

Valenzuela, E. (2006). Padres involucrados y uso de drogas: Un analisis empirico [Parent involvement and drug use: an empirical analysis]. Estudios Publicos, 101, 147-164.

Viana, V., Sinde, S., \& Saxton, J. C. (2008). Children's eating behaviour questionnaire: Associations with
BMI in Portuguese children. British Journal of Nutrition, 100, 445-450.

Villatoro, J., Medina-Mora, M., Hernández, M., Fleiz, C., Amador, N., \& Bermúdez, P. (2005). La encuesta de estudiantes de nivel medio y medio superior de la Ciudad de México: noviembre 2003: Prevalencias y evolución del consumo de drogas [Survey of students from middle and upper middle schools in Mexico City, November 2003: Prevalence and evolution of drug use]. Salud Mental, 28, 38-51.

Wagner, F., \& Anthony, J. C. (2002). Into the world of illegal drug use: Exposure opportunity and other mechanisms linking the use of alcohol, tobacco, marijuana, and cocaine. American Journal of Epidemiology, 155, 918-925.

Weden, M. M., Carpiano, R. M., \& Robert, S. A. (2008). Subjective and objective neighborhood characteristics and adult health. Social Science \& Medicine, 66, 1256-1270.

Wilson, N., Syme, S., Boyce, W., Battistich V., \& Selvin S. (2005). Adolescent alcohol, tobacco, and marijuana use: The influence of neighborhood disorder and hope. American Journal of Health Promotion, 20, 11-19.

Winstanley, E., Steinwachs, D., Ensminger, M., Latkin, C., Stitzer, M., \& Olsen, Y. (2008). The association of self-reported neighborhood disorganization and social capital with adolescent alcohol and drug use, dependence, and access to treatment. Drug Alcohol Dependence, 92, 173-182.

World Health Organization [WHO]. (2004). Global status report on alcohol 2004. Geneva, Switzerland: Author.

Youngblade, L. M., Theokas, C., Schulenberg, J., Curry, L., Huang, I-Ch., \& Novak, M. (2007). Risk and promotive factors in families, schools, and communities: A contextual model of positive youth development in adolescence. Pediatrics, 119, 47-53. 